\title{
Sequelae, persistent symptomatology and outcomes after COVID-19 hospitalization: the ANCOHVID multicentre 6-month follow- up study
}

Álvaro Romero-Duarte ${ }^{1}$, Mario Rivera-Izquierdo ${ }^{2,3,4^{*}}$ (1) Inmaculada Guerrero-Fernández de Alba ${ }^{2,5}$, Marina Pérez-Contreras ${ }^{6}$, Nicolás Francisco Fernández-Martínez ${ }^{7,8}$, Rafael Ruiz-Montero ${ }^{7,8}$, Álvaro Serrano-Ortiz ${ }^{7,8}$, Rocío Ortiz González-Serna ${ }^{7,8}$, Inmaculada Salcedo-Leal ${ }^{7,8}$, Eladio Jiménez-Mejías 3,9 and Antonio Cárdenas-Cruz ${ }^{1,10}$

\begin{abstract}
Background: Long-term effects of COVID-19, also called Long COVID, affect more than 10\% of patients. The most severe cases (i.e. those requiring hospitalization) present a higher frequency of sequelae, but detailed information on these effects is still lacking. The objective of this study is to identify and quantify the frequency and outcomes associated with the presence of sequelae or persistent symptomatology (SPS) during the 6 months after discharge for COVID-19.

Methods: Retrospective observational 6-month follow-up study conducted in four hospitals of Spain. A cohort of all 969 patients who were hospitalized with PCR-confirmed SARS-CoV-2 from March 1 to April 15, 2020, was included. We collected all the SPS during the 6 months after discharge reported by patients during follow-up from primary care records. Cluster analyses were performed to validate the measures. The main outcome measures were return to the Emergency Services, hospital readmission and post-discharge death. Surviving patients' outcomes were collected through clinical histories and primary care reports. Multiple logistic regression models were applied.

Results: The 797 (82.2\%) patients who survived constituted the sample followed, while the rest died from COVID19. The mean age was 63.0 years, 53.7\% of them were men and 509 (63.9\%) reported some sequelae during the first 6 months after discharge. These sequelae were very diverse, but the most frequent were respiratory (42.0\%), systemic (36.1\%), neurological (20.8\%), mental health (12.2\%) and infectious (7.9\%) SPS, with some differences by sex. Women presented higher frequencies of headache and mental health SPS, among others. A total of 160 (20.1\%) patients returned to the Emergency Services, 35 (4.4\%) required hospital readmission and 8 (1.0\%) died during follow-up. The main factors independently associated with the return to Emergency Services were persistent fever, dermatological SPS, arrythmia or palpitations, thoracic pain and pneumonia.
\end{abstract}

\footnotetext{
* Correspondence: mariorivera@ugr.es

${ }^{2}$ Service of Preventive Medicine and Public Health, Hospital Universitario

Clínico San Cecilio, Granada, Spain

${ }^{3}$ Department of Preventive Medicine and Public Health, University of

Granada, Avda. de la Investigación n¹1, 18016 Granada, Spain

Full list of author information is available at the end of the article
}

(c) The Author(s). 2021 Open Access This article is licensed under a Creative Commons Attribution 4.0 International License, which permits use, sharing, adaptation, distribution and reproduction in any medium or format, as long as you give appropriate credit to the original author(s) and the source, provide a link to the Creative Commons licence, and indicate if changes were made. The images or other third party material in this article are included in the article's Creative Commons licence, unless indicated otherwise in a credit line to the material. If material is not included in the article's Creative Commons licence and your intended use is not permitted by statutory regulation or exceeds the permitted use, you will need to obtain permission directly from the copyright holder. To view a copy of this licence, visit http://creativecommons.org/licenses/by/4.0/ The Creative Commons Public Domain Dedication waiver (http://creativecommons.org/publicdomain/zero/1.0/) applies to the data made available in this article, unless otherwise stated in a credit line to the data. 
Conclusions: COVID-19 cases requiring hospitalization during the first wave of the pandemic developed a significant range of mid- to long-term SPS. A detailed list of symptoms and outcomes is provided in this multicentre study. Identification of possible factors associated with these SPS could be useful to optimize preventive follow-up strategies in primary care for the coming months of the pandemic.

Keywords: COVID-19, Long COVID, Post-discharge, Sequelae, Persistent symptoms, Primary care, Follow-up

\section{Background}

During the so-called first wave of the COVID-19 pandemic, a rapid progression of the infection was reported in China and worldwide [1, 2]. This progression led to a significant number of severe cases that required hospitalization and intensive care [3]. Immediately, major efforts were made internationally in order to identify the main symptoms to optimize diagnosis [4-6] and the main prognostic factors to improve treatment and healthcare strategies [7-10]. A wide and multifaceted range of clinical manifestations was identified, including respiratory, gastrointestinal, neurological and cardiovascular symptoms, among others [11].

After the first wave, new efforts focused on identifying the potential short-term sequelae following COVID-19 infection, especially in higher-risk cases requiring longer hospital care, the so-called post-discharge syndrome [12]. Among the most frequent, respiratory and neurological sequelae [13], cutaneous signs [14] or headache [15] have been described. The lethality and factors related to COVID-19 are being thoroughly analysed but, given the high number of hospitalized patients and the potential morbidity it could generate, further research on possible sequelae after hospitalization is still required.

However, there has not yet been sufficient time to evaluate the long-term effects of COVID-19 in these severe cases requiring hospitalization. To date, there are very few studies that provide detailed information on the wide range of sequelae and persistent symptoms (SPS) after 6 months of follow-up [16]. Some studies describe the presence of persistent symptoms after 3 months of follow-up [12, 17-20], but further evidence is still needed.

Furthermore, there is no information in the current literature on possible outcomes associated with these SPS (death after discharge, readmission to hospital or emergency care) that would be useful for improving preventive measures and primary care follow-up after discharge. Therefore, the design of high-risk patient profiles and the individualization of clinical follow-up according to risk and SPS could be useful for the correct management in primary care follow-up and discharge criteria, which are necessary in a context of high healthcare pressure.

The objective of this study was twofold. First, we aimed to identify and quantify the SPS during the 6 months after discharge for COVID-19. Second, we aimed to analyse the association of SPS with negative outcomes (return to the Emergency Services, hospital readmission and death) in the 6 months following discharge to plan differential preventive follow-up strategies.

\section{Methods}

\section{Study design and setting}

A 6-month retrospective longitudinal observational follow-up study was designed, according to Strengthening the Reporting of Observational Studies in Epidemiology (STROBE) guidelines (Additional file 1). The study sample consisted of the cohort of patients admitted to the selected hospitals in four cities in Andalusia, Spain (Córdoba, Granada, Jaén and Puerto Real) from March 1 to April 15, 2020. Inclusion criteria included confirmed polymerase chain reaction (PCR) to SARS-CoV-2 (confirmed cases according to the Spanish Ministry of Health). Therefore, patients with compatible clinical symptoms and imaging test (suspected cases) but negative PCR were not included. In addition, only patients who required hospitalization were considered (patients identified in the Emergency Services who did not require hospitalization were excluded). All cases were followed up for 6 months after discharge. Therefore, the follow-up of the study concluded on January 5, 2021.

\section{Data source and variables}

Hospitalization medical records were consulted to collect data on sociodemographic, clinical, therapeutic and evolution factors of COVID-19 patients. To collect information on SPS after discharge, primary care records were consulted. Follow-up consultation records and periodic telephonic reports scheduled from primary care standardized in Andalusia were consulted. Data from hospital specialties (pneumology and infectious diseases services) were also consulted to obtain more information on SPS. The SPS collected occurred at any time after discharge and before the outcomes. Therefore, SPS registered on return to Emergency Services or readmission were not considered as source of SPS information, in an attempt to avoid potential selection bias. Similarly, when an outcome occurred more than once (e.g. return to the 
Emergency Services several times), only the SPS reported before the first return were considered for the analysis to avoid reverse causality. Finally, data on dependency and residential care centres were obtained by accessing the Andalusian Epidemiological Surveillance System (SVEA). Obesity and smoking were not considered for the analyses because most of the records did not include these variables. The variables included in the study were:

- Sociodemographic variables: sex, age, country, residence (living at home or at specific centres), dependency for activities of daily living (DADL)

- Admission variables: admission to the intensive care unit (ICU) or hospitalization, time of hospitalization

- Clinical variables: past medical history, analytical results, presence of concomitant infections, prognostic scores as CURB-65 (confusion, blood urea, respiratory rate, blood pressure and age $>65$ ) and the Sequential Organ Failure Assessment (SOFA), candidate to cardiopulmonary resuscitation (CPR), treatments during hospitalization, outcome (discharge or intrahospital death)

- SPS variables: SPS information reported in primary care reports, follow-up consultation reports and hospital specialty reports were extensively collected by the researchers and then classified into:

General or systemic SPS: persistence of fever, fatigue, muscle weakness, musculoskeletal pain, general malaise, oedema and pressure ulcers

Respiratory SPS: persistent dyspnoea, rib pain, thoracic pain, persistent cough, persistent pharyngeal symptoms

Neurological SPS: ICU-related polyneuropathy, headache, paraesthesia, movement disturbances, disorientation or confusion, persistent anosmia or dysgeusia

Mental health SPS: depressive symptoms, anxiety symptoms, sleep disturbances

Haematological SPS: anaemia, thrombotic manifestations

Dermatological SPS: pruritus, alopecia, exanthema, eczema

Nephrological SPS: renal insufficiency de novo Urological SPS: dysuria, haematuria, oliguria

Endocrinological SPS: uncontrolled glycaemia, caloric malnutrition

Otorhinolaryngological SPS: hypoacusis, otalgia, vertigo symptoms

Ophthalmological SPS: diplopia, conjunctivitis, visual loss

Digestive SPS: persistent nausea, vomits, diarrhoea, constipation, anorexia, abdominal pain
Cardiovascular SPS: syncope or hypotension, arrythmia

Infectious SPS (superinfections after COVID-19 resolution): urinary tract infections (UTI), pneumonia, mycosis, phlebitis

- Follow-up outcomes (6 months after discharge): readmission to Emergency Services, readmission to hospitalization, death

A detailed description and definitions of all these SPS are presented in Additional file 2: Table S1.

\section{Statistical analyses}

A descriptive analysis of the main sociodemographic and clinical variables of the study was conducted, stratified by outcomes (return to Emergency Services, readmission to hospital and death after discharge). The frequency of SPS in surviving patients was described in detail and stratified by sex. Hierarchical cluster analyses of the SPS were made in order to provide evidence of the validity of the information collected and to explore possible unknown associations between different SPS. This analysis was applied to cluster variables rather than observations, using a dissimilarity measure based on Euclidean distances.

Bivariant analyses were then conducted to identify differences in SPS between men and women, and according to the three outcomes. T-test was applied for quantitative variables (mean differences) and chi-squared tests for qualitative variables. When the application conditions were not met, Mann-Whitney and Fisher exact tests were conducted, respectively.

Multiple logistic regression models were applied. The three outcomes were analysed as dependent variables in three models, and SPS were analysed as independent variables. Crude and adjusted odds ratios (cOR and aOR, respectively) were calculated. The models were adjusted for sex, age and sociodemographic and clinical variables, when possible. All statistical analyses were performed using Stata (StataCorp $)^{\oplus}$, version 15.0.

\section{Ethical considerations}

The ethical implications of the study were considered according to the principles of the Declaration of Helsinki Declaration. The study was approved by the Provincial Research Ethical Committee of Granada on October 1, 2020. As this was a retrospective observational study, the informed consent was not possible. The database was anonymized, and no identification data was used in the analyses.

\section{Results}

Sociodemographic and clinical variables

Table 1 shows the distribution of the main sociodemographic variables recorded in the study, stratified by 
Table 1 Sociodemographic and clinical variables of the followed cohort $(n=797)$ stratified for outcomes of the study

\begin{tabular}{|c|c|c|c|c|}
\hline \multirow[t]{2}{*}{ Variable } & $\begin{array}{l}\text { Total sample followed } \\
(n=797)\end{array}$ & $\begin{array}{l}\text { Return to Emergency Services } \\
(n=160)\end{array}$ & $\begin{array}{l}\text { Readmission to hospital } \\
(n=35)\end{array}$ & $\begin{array}{l}\text { Death after discharge } \\
(n=8)\end{array}$ \\
\hline & $\mathrm{N}(\%), \mathrm{x}(\mathrm{s})$ & $\mathrm{N}(\%), \mathrm{x}(\mathrm{s})$ & $\mathrm{N}(\%), \mathrm{x}(\mathrm{s})$ & $\mathrm{N}(\%), \mathrm{x}(\mathrm{s})$ \\
\hline Men & $428(53.7)$ & $85(53.1)$ & $15(42.9)$ & $3(37.5)$ \\
\hline Age: $\times(s)$ & $63.0(14.4)$ & $61.7(15.3)$ & $67.5(16.9)$ & $82.1(4.2)$ \\
\hline \multicolumn{5}{|l|}{ Age categories } \\
\hline$<40$ years & $45(5.6)$ & $11(6.9)$ & $2(5.7)$ & $0(0)$ \\
\hline $40-50$ years & $93(11.7)$ & $20(12.5)$ & $0(0)$ & $0(0)$ \\
\hline $50-60$ years & $181(22.7)$ & $39(24.4)$ & $8(22.9)$ & $0(0)$ \\
\hline $60-70$ years & $206(25.8)$ & $43(26.9)$ & $10(28.6)$ & $0(0)$ \\
\hline $70-80$ years & $164(20.6)$ & $25(15.6)$ & $6(17.1)$ & $2(25.0)$ \\
\hline $80-90$ years & 95 (11.9) & $16(10.0)$ & $5(14.3)$ & $6(75.0)$ \\
\hline$>90$ years & $13(1.6)$ & $6(3.8)$ & $4(11.4)$ & $0(0)$ \\
\hline \multicolumn{5}{|l|}{ Setting } \\
\hline Granada & $361(45.3)$ & $75(46.9)$ & $18(51.4)$ & $4(50.0)$ \\
\hline Córdoba & $186(23.3)$ & $40(25.0)$ & $6(17.1)$ & $1(12.5)$ \\
\hline Cádiz & $27(3.4)$ & $5(3.1)$ & $0(0)$ & $0(0)$ \\
\hline Jaén & $223(28.0)$ & $40(25.0)$ & $11(31.4)$ & $3(37.5)$ \\
\hline Any comorbidity & $538(67.5)$ & $104(65.0)$ & $23(65.7)$ & $7(87.5)$ \\
\hline Hypertension & $409(51.3)$ & $77(48.1)$ & $18(51.4)$ & $6(75.0)$ \\
\hline Diabetes mellitus & 166 (20.8) & 35 (21.9) & $7(20.0)$ & $1(12.5)$ \\
\hline Cardiovascular disease & $164(20.6)$ & $40(25.0)$ & $13(37.1)$ & $3(37.5)$ \\
\hline Pneumopathy & $107(13.4)$ & $22(13.8)$ & $3(8.6)$ & $2(25.0)$ \\
\hline COPD & $40(5.0)$ & $7(4.4)$ & $1(2.9)$ & $1(12.5)$ \\
\hline Asthma & $59(7.4)$ & $11(6.9)$ & $1(2.9)$ & $0(0)$ \\
\hline Chronic kidney disease & $69(8.7)$ & $14(8.8)$ & $5(14.3)$ & $3(37.5)$ \\
\hline Autoimmune disease & $61(7.7)$ & $17(10.6)$ & $2(5.7)$ & $1(12.5)$ \\
\hline Immunosuppression & $36(4.5)$ & $10(6.3)$ & $2(5.7)$ & $0(0)$ \\
\hline Active neoplasm & $32(4.0)$ & $6(3.8)$ & $1(2.9)$ & $1(12.5)$ \\
\hline Polymedication $^{\text {a }}$ & $295(37.0)$ & $68(42.5)$ & $20(57.1)$ & $6(75.0)$ \\
\hline Dependence & $120(15.1)$ & $29(18.1)$ & $14(40.0)$ & $5(62.5)$ \\
\hline Living at home & $712(89.3)$ & $138(86.3)$ & $24(68.7)$ & $5(62.5)$ \\
\hline Hospitalization days x (s) & $15.0(13.5)$ & $16.6(13.8)$ & $22.3(20.0)$ & $19.4(12.3)$ \\
\hline Ferritin at admission $\times(\mathrm{s})$ & $685.0(952.2)$ & $537.1(546.5)$ & $378.8(308.5)$ & $372.8(502.9)$ \\
\hline Unknown & $108(13.6)$ & $23(14.4)$ & $4(11.4)$ & $1(12.5)$ \\
\hline Abnormal TR at admission & $667(83.7)$ & $128(80.0)$ & $23(65.7)$ & $7(87.5)$ \\
\hline Unknown & $36(4.5)$ & $8(5.0)$ & $3(8.6)$ & $0(0)$ \\
\hline CRS & $298(37.4)$ & $55(34.4)$ & $11(31.4)$ & $2(25.0)$ \\
\hline Unknown & $62(7.8)$ & $13(8.1)$ & $3(8.6)$ & $0(0)$ \\
\hline Concomitant infection ${ }^{\mathrm{b}}$ & $111(13.9)$ & $29(18.1)$ & $9(25.7)$ & $1(12.5)$ \\
\hline \multicolumn{5}{|l|}{ CURB-65 } \\
\hline 0 & $221(27.7)$ & $45(28.1)$ & $4(11.4)$ & $0(0)$ \\
\hline 1 & $241(30.2)$ & $44(27.5)$ & $9(25.7)$ & $1(12.5)$ \\
\hline 2 & $130(16.3)$ & $28(17.5)$ & 10 (28.6) & $5(62.5)$ \\
\hline 3 & $21(2.6)$ & $6(3.8)$ & $1(2.9)$ & $0(0)$ \\
\hline
\end{tabular}


Table 1 Sociodemographic and clinical variables of the followed cohort $(n=797)$ stratified for outcomes of the study (Continued)

\begin{tabular}{|c|c|c|c|c|}
\hline \multirow[t]{2}{*}{ Variable } & $\begin{array}{l}\text { Total sample followed } \\
(n=797)\end{array}$ & $\begin{array}{l}\text { Return to Emergency Services } \\
(n=160)\end{array}$ & $\begin{array}{l}\text { Readmission to hospital } \\
(n=35)\end{array}$ & $\begin{array}{l}\text { Death after discharge } \\
(n=8)\end{array}$ \\
\hline & $\mathrm{N}(\%), \mathrm{x}(\mathrm{s})$ & $N(\%), x(s)$ & $\mathrm{N}(\%), \mathrm{x}(\mathrm{s})$ & $\mathrm{N}(\%), \mathrm{x}(\mathrm{s})$ \\
\hline 4 & $2(0.3)$ & $0(0)$ & $0(0)$ & $0(0)$ \\
\hline Unknown & $182(22.8)$ & $37(23.1)$ & $11(31.4)$ & $2(25.0)$ \\
\hline Not candidate for CPR & $138(17.3)$ & $31(19.4)$ & $11(31.4)$ & $5(62.5)$ \\
\hline Unknown & $221(27.7)$ & 37 (23.1) & $11(31.4)$ & $2(25.0)$ \\
\hline Hydroxychloroquine & $704(88.3)$ & $137(85.6)$ & $26(74.3)$ & $5(62.5)$ \\
\hline Lopinavir/ritonavir & $488(61.2)$ & $94(58.8)$ & $21(60.0)$ & $1(12.5)$ \\
\hline Azithromycin & $603(65.7)$ & $117(73.1)$ & $24(68.6)$ & $4(50.0)$ \\
\hline Corticosteroid boluses & $285(35.8)$ & 60 (37.5) & $11(31.4)$ & $3(37.5)$ \\
\hline Tocilizumab & $82(10.3)$ & $18(11.3)$ & $6(17.1)$ & $1(12.5)$ \\
\hline Antibiotics & 477 (59.8) & 99 (61.9) & $21(60.0)$ & $3(37.5)$ \\
\hline ACEI/ARA-II & $221(27.7)$ & $43(26.9)$ & $12(34.3)$ & $4(50.0)$ \\
\hline ICU admission & $81(10.8)$ & $16(10.0)$ & $3(8.6)$ & $0(0)$ \\
\hline Total & $797(100)$ & $160(20.1)$ & $35(4.4)$ & $8(1.0)$ \\
\hline
\end{tabular}

ACEI/ARA-II angiotensin-converting enzyme inhibitor/angiotensin II receptor antagonists, COPD chronic obstructive pulmonary disease, CRS cytokine release syndrome, CURB-65 prognostic score based on confusion, blood urea, respiratory rate, blood pressure and age, ICU intensive care unit, TR thorax radiography. Missing values are presented as "unknown". Data are presented as mean (x) and standard deviation (s) for quantitative variables and absolute frequency ( $\mathrm{n}$ ) and

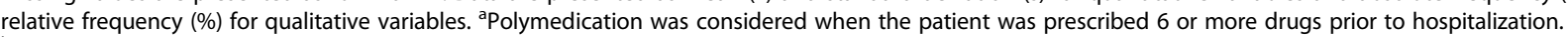

${ }^{b}$ Concomitant infection was considered when, during hospitalization, other infectious diseases different from COVID-19 was identified

outcome. Of the total cohort $(n=969)$, the subgroup of patients who were discharged alive $(n=797)$ constituted the sample followed. The rest (17.8\%) represented inhospital mortality from COVID-19 in our cohort. The 8 patients who died after discharge showed older age (82.1 years) and higher frequency of comorbidities and dependence.

\section{Frequency of SPS during the 6-month follow-up}

Of the cohort followed, 509 patients (63.9\%) presented any SPS during the follow-up. The prevalence of the different SPS, classified by organs and systems, is presented in Table 2. It can be seen that the frequency of SPS was high and varied. The most frequent groups of SPS were respiratory (42.0\%), systemic or general (36.1\%), digestive (26.2\%), neurological (20.8\%), mental health (12.2\%), dermatological $(9.3 \%)$, infectious $(7.9 \%)$, cardiovascular (5.8\%), ophthalmological (4.6\%), nephrological (4.5\%), haematological (4.4\%) and urological (4.3\%).

In order to provide evidence of the validity of the information collected, a cluster analysis was performed for all SPS (Fig. 1). The dendrogram for specific SPS showed an association between dyspnoea and fatigue, depressive and anxiety symptoms, exanthema and pruritus, vomiting and nausea, nephrological and urological SPS, and both with urinary tract infection. Figure 1 shows the SPS associations in the vertical (ordered) edge: the stronger the association between the SPS, the lower the line linking them. Therefore, "vomiting" and "nausea" should be clearly associated if the data have been properly collected, and the same for the other logical associations shown. Therefore, these cluster associations support the validity of the data collected.

\section{Outcomes}

We analysed outcomes after 6 months of follow-up in the patients who survived the first COVID-19 hospitalization $(n=797)$ : return to Emergency Services, hospital readmission and death after discharge. The main SPS associated with the outcomes in the bivariant analyses are shown in Additional file 2: Table S2. There were several SPS that showed association $(P<0.05)$ with all outcomes analysed, such as persistent fever, pressure ulcers, headache, nephrological SPS, hypotension or syncope and superinfection, especially pneumonia (see Additional file 2 for full details).

The main factors associated with return to the Emergency Services $(n=160)$ in the adjusted logistic regression models were persistent fever, thoracic pain, dermatological SPS, arrythmia or palpitations, superinfection and pneumonia (Additional file 2: Table S3).

For hospital readmissions $(n=35)$, the main SPS associated with this outcome in our analysis were persistent fever, any nephrological SPS, superinfection and pneumonia. However, we observed large confidence intervals indicating unstable standard errors (Additional file 2: Table S4).

As only 8 post-discharge deaths were observed, no associations were calculated for this outcome due to limited external validity. The main sociodemographic or 
Table 2 Frequency of sequelae or persistent symptomatology (SPS) during the 6 months after hospital discharge in surviving patients $(n=797)$ stratified by sex

\begin{tabular}{|c|c|c|c|c|}
\hline \multirow[t]{2}{*}{$\begin{array}{l}\text { Sequelae or persistent } \\
\text { symptoms (SPS) }\end{array}$} & \multirow{2}{*}{$\begin{array}{l}\begin{array}{l}\text { Total } \\
(n=797)\end{array} \\
\text { N (\%), x (s) }\end{array}$} & \multirow{2}{*}{$\begin{array}{l}\text { Men } \\
(n=428) \\
N(\%), x(s)\end{array}$} & $\begin{array}{l}\text { Women } \\
(n=369)\end{array}$ & \multirow[t]{2}{*}{$P$-value } \\
\hline & & & $\mathrm{N}(\%), \mathrm{x}(\mathrm{s})$ & \\
\hline Any SPS & $509(63.9)$ & $267(62.4)$ & $242(65.6)$ & 0.348 \\
\hline Any systemic/general SPS & $288(36.1)$ & $140(32.7)$ & $148(40.1)$ & $0.030^{*}$ \\
\hline Persistent fever & $56(7.0)$ & $28(6.5)$ & $28(7.6)$ & 0.565 \\
\hline Fatigue & $176(22.1)$ & $81(18.9)$ & $95(25.7)$ & $0.021^{*}$ \\
\hline Muscle weakness & $30(3.8)$ & $20(4.7)$ & $10(2.7)$ & 0.147 \\
\hline Musculoskeletal pain & $122(15.3)$ & $53(12.4)$ & 69 (18.7) & $0.014^{*}$ \\
\hline General malaise & $34(4.3)$ & $18(4.2)$ & $16(4.3)$ & 0.928 \\
\hline Oedema & $23(2.9)$ & $12(2.8)$ & $11(3.0)$ & 0.881 \\
\hline Pressure ulcers & $14(1.8)$ & $6(1.4)$ & $8(2.2)$ & 0.412 \\
\hline Any respiratory SPS & $335(42.0)$ & $183(42.8)$ & $152(41.2)$ & 0.655 \\
\hline Dyspnoea & $223(28.0)$ & $128(29.9)$ & $95(25.7)$ & 0.192 \\
\hline Rib pain & $36(4.5)$ & $17(4.0)$ & $19(5.1)$ & 0.425 \\
\hline Thoracic pain & $53(6.6)$ & $28(6.5)$ & $25(6.8)$ & 0.895 \\
\hline Persistent cough & $153(19.2)$ & 77 (20.9) & $76(17.8)$ & 0.266 \\
\hline Persistent pharyngeal symptoms & $67(8.4)$ & $33(7.7)$ & $34(9.2)$ & 0.446 \\
\hline Any neurological SPS & $166(20.8)$ & $84(19.6)$ & $82(22.2)$ & 0.368 \\
\hline ICU-related polyneuropathy ${ }^{a}$ & $25(3.1)$ & $16(3.7)$ & $9(2.4)$ & 0.294 \\
\hline Headache & $42(5.3)$ & $14(3.3)$ & $28(7.6)$ & $0.007^{*}$ \\
\hline Paraesthesia & $27(3.4)$ & $18(4.2)$ & $9(2.4)$ & 0.169 \\
\hline Movement disturbances & $27(3.4)$ & $13(3.0)$ & $14(3.8)$ & 0.556 \\
\hline Disorientation or confusion & $21(2.6)$ & $11(2.6)$ & $10(2.7)$ & 0.902 \\
\hline Persistent anosmia or dysgeusia & $57(7.2)$ & $30(7.0)$ & $27(7.3)$ & 0.987 \\
\hline Any mental health SPS & $97(12.2)$ & $39(9.1)$ & $58(15.7)$ & $0.004^{*}$ \\
\hline Depressive symptoms & $35(4.4)$ & $11(2.6)$ & $24(6.5)$ & $0.007^{*}$ \\
\hline Anxiety symptoms & $54(6.8)$ & $18(4.2)$ & $36(9.8)$ & $0.002^{*}$ \\
\hline Sleep disturbances & $39(4.9)$ & $22(5.1)$ & $17(4.6)$ & 0.728 \\
\hline Any haematological SPS & $35(4.4)$ & $15(3.5)$ & $20(5.4)$ & 0.188 \\
\hline Thrombotic manifestations & $25(3.1)$ & $9(2.1)$ & $16(4.3)$ & 0.071 \\
\hline Any dermatological SPS & $74(9.3)$ & $34(7.9)$ & $40(10.8)$ & 0.160 \\
\hline Pruritus & $20(2.5)$ & $11(2.6)$ & $9(2.4)$ & 0.906 \\
\hline Alopecia & $24(3.0)$ & $1(0.2)$ & $23(6.2)$ & $<0.001^{*}$ \\
\hline Exanthema & $25(3.1)$ & $17(4.0)$ & $8(2.2)$ & 0.145 \\
\hline Eczema & $12(1.5)$ & $8(1.9)$ & $4(1.1)$ & 0.364 \\
\hline Any nephrological SPS & $36(4.5)$ & $18(4.2)$ & $18(4.9)$ & 0.649 \\
\hline Renal insufficiency de novo & $7(0.9)$ & $4(0.9)$ & $3(0.8)$ & 0.854 \\
\hline Any urological SPS & $34(4.3)$ & $21(4.9)$ & $13(3.4)$ & 0.335 \\
\hline Any endocrinological SPS & $12(1.5)$ & $10(2.3)$ & $2(0.5)$ & $0.038^{*}$ \\
\hline Glycaemia uncontrol & $7(0.9)$ & $6(1.4)$ & $1(0.3)$ & 0.088 \\
\hline Any otorhinolaryngological SPS & $25(3.1)$ & $8(1.9)$ & $17(4.6)$ & $0.027^{*}$ \\
\hline Vertigo symptoms & $15(1.9)$ & $3(0.7)$ & $12(3.3)$ & $0.008^{*}$ \\
\hline Otoacoustic symptoms & $10(1.3)$ & $4(0.9)$ & $6(1.6)$ & 0.382 \\
\hline Ophthalmological SPS & $37(4.6)$ & $16(3.7)$ & $21(5.7)$ & 0.191 \\
\hline
\end{tabular}


Table 2 Frequency of sequelae or persistent symptomatology (SPS) during the 6 months after hospital discharge in surviving patients $(n=797)$ stratified by sex (Continued)

\begin{tabular}{|c|c|c|c|c|}
\hline \multirow[t]{2}{*}{$\begin{array}{l}\text { Sequelae or persistent } \\
\text { symptoms (SPS) }\end{array}$} & \multirow{2}{*}{$\begin{array}{l}\text { Total } \\
(n=797) \\
\mathrm{N}(\%), \times(s)\end{array}$} & \multirow{2}{*}{$\begin{array}{l}\text { Men } \\
(n=428) \\
N(\%), \times(s)\end{array}$} & \multirow{2}{*}{$\begin{array}{l}\begin{array}{l}\text { Women } \\
(n=369)\end{array} \\
\mathrm{N}(\%), \times(\mathrm{s})\end{array}$} & \multirow[t]{2}{*}{$P$-value } \\
\hline & & & & \\
\hline Digestive symptoms & $129(26.2)$ & $63(14.7)$ & $66(17.9)$ & 0.226 \\
\hline Diarrhoea & $82(10.3)$ & $35(8.2)$ & $47(12.7)$ & $0.035^{*}$ \\
\hline Constipation & $14(1.8)$ & $7(1.6)$ & $7(1.9)$ & 0.779 \\
\hline Vomiting & $16(2.0)$ & $3(0.7)$ & $13(3.5)$ & $0.005^{*}$ \\
\hline Abdominal pain & $43(5.4)$ & $20(4.7)$ & $23(6.2)$ & 0.331 \\
\hline Anorexia & $8(1.0)$ & $4(0.9)$ & $4(1.1)$ & 0.833 \\
\hline Cardiovascular SPS & $46(5.8)$ & $26(6.1)$ & $20(5.4)$ & 0.693 \\
\hline Hypotension or syncope & $23(2.9)$ & $14(3.3)$ & $9(2.4)$ & 0.484 \\
\hline Arrythmia or palpitations & $25(3.1)$ & $13(3.0)$ & $12(3.3)$ & 0.862 \\
\hline Superinfection & $63(7.9)$ & $30(7.0)$ & $33(8.9)$ & 0.313 \\
\hline Urinary tract infection & $31(3.9)$ & $15(3.5)$ & $16(4.3)$ & 0.545 \\
\hline Pneumonia & $6(0.8)$ & $4(0.9)$ & $2(0.5)$ & 0.691 \\
\hline Mycosis & $11(1.4)$ & $6(1.4)$ & $5(1.4)$ & 0.955 \\
\hline Return to Emergency Services & $160(20.3)$ & $85(20.0)$ & 75 (20.7) & 0.818 \\
\hline Readmission to hospital $^{b}$ & $35(12.1)$ & $15(9.9)$ & $20(14.5)$ & 0.227 \\
\hline Death after discharge & $8(1.0)$ & $3(0.7)$ & $5(1.4)$ & 0.356 \\
\hline Total & $797(100)$ & $428(53.7)$ & $369(46.3)$ & - \\
\hline
\end{tabular}

ICU intensive care unit. The SPS presented in $<5$ patients (prevalence $<0.6 \%$ ) were not considered in the analyses to avoid saturation of information and

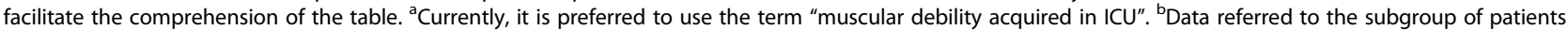
that returned to Emergency Services $(n=160) .{ }^{*} P<0.05$ of chi-squared tests comparing sex and each SPS

clinical factor associated with mortality after discharge was older age. After adjusting for age, most associations disappeared (Additional file 2: Table S5).

The main SPS associated with the outcomes studied in the adjusted models are summarized and illustrated in Fig. 2.

\section{Discussion}

In this study, we described the main characteristics of discharged patients $(n=797)$ from a cohort of 969 patients who required hospitalization during the first months of the COVID-19 pandemic in four hospitals in southern Spain. We provided a detailed list of SPS during the 6 months after discharge and described which of these SPS are associated with negative outcomes (return to Emergency Services, hospital readmission and post-discharge death).

\section{Characteristics of the cohort}

The characteristics of our sample are consistent with other cohorts of patients hospitalized during the first wave of the COVID-19 pandemic in different countries. Therefore, the mean age of our sample (63.0) and the sex distribution ( $53.7 \%$ of men) are similar to previous studies such as the recently published Mediterranean cohort study [18], studies conducted in Italy [21] and Brazil [22] and other Spanish multicentre studies [23], although slightly different from other national reports
[24]. For example, Carfi et al. showed 56.5 mean age and $63 \%$ of men [20] and Garrigues et al. showed 58 mean age and $63 \%$ of women [12].

Our higher mean age could be partially explained by the high life expectancy in our country and by an ageing reference population in South Spain [25]. Also, during the first weeks of the pandemic in Spain, a high number of elderly patients from residential care homes were hospitalized [26], given that exhaustive prevention and control measures had not yet been established. The inhospital mortality of our cohort was $17.8 \%$, data similar to those reported in other studies in the same period performed in New York [27] but lower than in other studies performed in Wuhan [28] and Spain [23]. Similarly, the proportion of patients requiring intensive care was $12.1 \%$, which is consistent with large patient cohorts in the USA (14.2\%) [27].

Since the sample of our study is composed of the most severe COVID-19 cases (those requiring hospitalization), they presented a high frequency of previous diseases, polymedication and dependency for daily living activities, as shown in Table 1.

\section{Frequency of SPS}

We showed $63.9 \%$ of SPS during the 6 months after discharge, similar to other studies. A study conducted in 


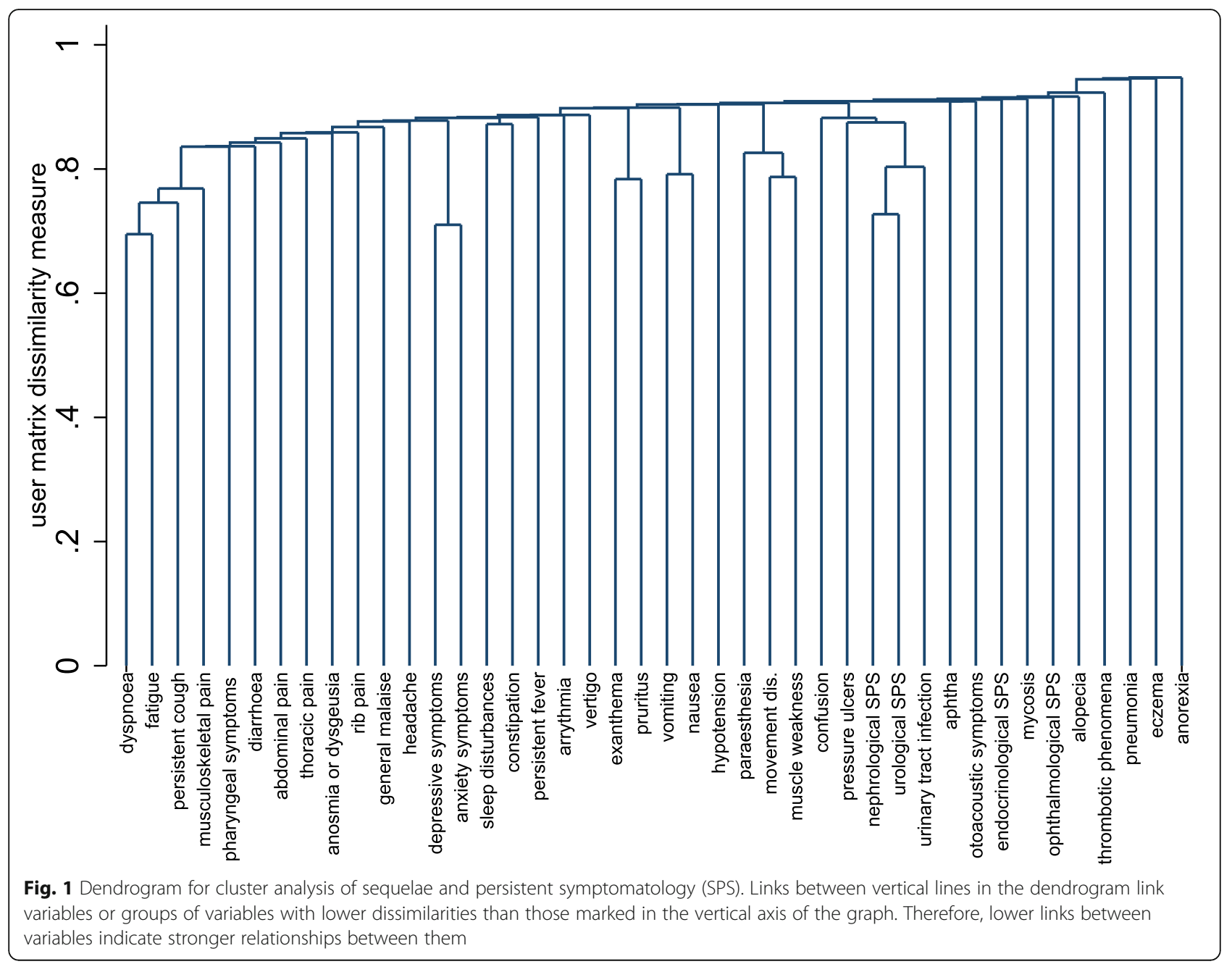

Spain with 14 weeks of follow-up showed $50 \%$ postacute COVID-19 syndrome [18]. Another study conducted in France showed 55\% persistent symptoms after a mean of 110 days of follow-up [12] and $62.5 \%$ of SPS was present 50 days after discharge [19]. However, other series have reported up to $68 \%$ at 2 months [29], $87 \%$ at 2 months [20] and $87 \%$ at 3 months [17].

Table 2 lists all reported SPS and their prevalence stratified by sex. The most relevant were as follows.

\section{Respiratory SPS}

Dyspnoea was the most frequent specific SPS in our cohort $(28.0 \%)$. These data are lower than other reported frequencies, 31.4\% [19] and 43.4\% [20]. All reported series concur that dyspnoea and fatigue are the most frequent SPS after COVID-19 [12, 18, 20, 30]. A possible explanation for these symptoms could be the persistence of fibrotic residual pulmonary areas. Furthermore, fibrosis would be the result of an ineffective organization stage after the initial acute inflammatory response [31]. Thoracic pain $(6.6 \%)$ was associated with return to the
Emergency Services. Therefore, the presence of this symptom could warn of potential severity.

\section{Systemic SPS}

The high prevalence of fatigue (22.1\%) is consistent with previous series [20,30,32]. A high frequency of musculoskeletal pain (15.3\%) was also observed. Both symptoms could be explained by the systemic inflammatory response generated by COVID-19 [33, 34] and by natural recovery after hospitalization processes [34]. Persistent fever $(7.0 \%)$ and pressure ulcers (1.8\%), generally occurring in patients with longer hospitalization time, were associated with negative outcomes. Therefore, the presence of these signs could be related to particularly vulnerable patients that require more intense monitoring.

\section{Digestive SPS}

Digestive SPS were very frequent (26.2\%), especially diarrhoea (10.3\%) and abdominal pain (5.4\%), according to previous series [20]. Some digestive SPS, such as 


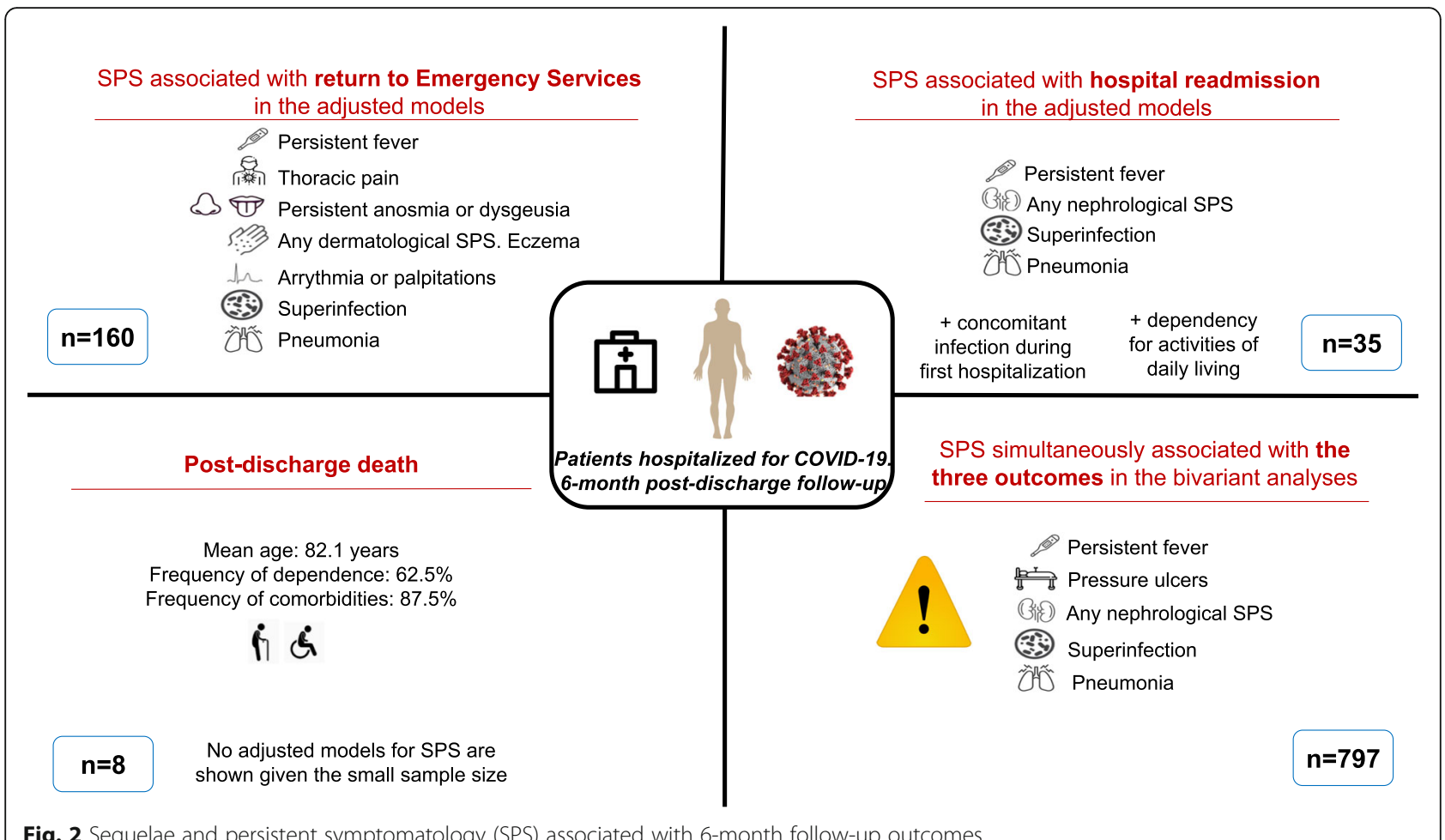

vomiting ( $2.0 \%$ in our cohort), diarrhoea, nausea, hepatitis or abdominal pain, have been associated with COVID-19 treatment, as adverse drug reactions [35]. According to other studies, hepatic injuries may also be associated with COVID-19 [36].

\section{Neurological SPS}

Several recent studies pointed the high frequency of neurological SPS after COVID-19 [37, 38]. In our cohort (20.8\%), the most prevalent SPS was persistent anosmia or dysgeusia $(7.2 \%)$, which showed a protective association with negative outcomes. Headache (5.3\%) was associated with the outcomes, and disorientation or confusion (2.6\%) was associated with hospital readmission. The presence of these symptoms could predict a worse evolution and, therefore, require timely preventive measures. Finally, the high prevalence of paraesthesia (3.4\%) and movement (3.4\%) disorders, such as dystonia or tremor, was surprising. These SPS were recently pointed out as potentially involved in COVID-19 complications [38]. A wide variety of neurological manifestations (e.g. encephalopathy, encephalitis, seizures, cerebrovascular events, acute polyneuropathy, etc.) have been associated with COVID-19 [39], some of them also confirmed at the neuropathological level [40]. Apart from symptoms, COVID-19 has also been linked to a variety of severe neurological complications, especially Guillain-Barré syndrome [41].

\section{Mental health SPS}

The high frequency of mental health symptoms in our cohort (12.2\%) reflects the alarm expressed by several authors $[42,43]$ on the importance of preventing and identifying mental health SPS after hospitalization for COVID-19. These symptoms could be overestimated due to isolation during the hospitalization period and lockdown measures during the first wave of the pandemic [44, 45], but also due to other simultaneous familiar cases and admissions as well as high uncertainty during the first months. We found a high frequency of anxiety (6.8\%), sleep disturbances (4.9\%) and depressive symptoms (4.4\%), especially higher in women.

\section{Dermatological SPS}

This group represented $9.3 \%$ of our cohort. Although a high prevalence of dermatological symptoms related to COVID-19 has been reported since the beginning of the pandemic [46], we did not find any studies reporting these frequencies in follow-up cohorts. In our study, these symptoms were associated with return to the Emergency Services, possibly because they are visible and worrying to patients, but we found no association with mortality or hospital readmission. The most frequent SPS in our study was exanthema (3.1\%). The high presence of alopecia (3.0\%) in our study, especially higher in women, is noteworthy. 


\section{Superinfection}

One of the most intriguing findings of our study was the high prevalence of superinfection (7.9\%) during the 6 months after discharge from COVID-19 and its strong association with negative outcomes. It is possible that COVID-19 produces medium-term immunosuppression leading to superinfection, especially pneumonia, as reported in other works [33, 34]. This is consistent with other viral infections such as influenza, especially bacterial respiratory superinfections. The most frequent SPS in our cohort were urinary tract infection $(3.9 \%)$ and mycosis $(1.4 \%)$, which were not associated with negative outcomes. However, the presence of pneumonia (0.8\%) led to negative outcomes in the adjusted analyses, thus becoming one of the main alarm symptoms proposed in our study. We were able to identify Streptococcus pneumoniae as one of the agents involved in 2 of the 6 cases of pneumonia, but no other etiological diagnosis was available.

\section{Cardiovascular SPS}

Several authors have reported the potential cardiovascular effects of COVID-19 [47, 48], as occur with other systemic viral infections like influenza [49]. Longitudinal studies reported frequencies of cardiovascular SPS higher than $10 \%$ [50]. In our sample, $5.8 \%$ of patients reported some cardiovascular SPS. Specifically, arrythmia or palpitations $(3.1 \%)$ and hypotension or syncope $(2.9 \%)$ were also associated with negative outcomes.

\section{Ophthalmological SPS}

We present the highest frequency of reported ophthalmological SPS in a cohort of hospitalized patients $(4.6 \%)$, including conjunctivitis and vision loss, among others. Although not associated with negative outcomes, our results suggest that COVID-19 may be implicated in ophthalmic outcomes, as noted by other authors [51].

\section{Nephrological SPS}

In our cohort, $4.5 \%$ of patients presented nephrological SPS and $0.9 \%$ showed de novo renal insufficiency. It is possible that some nephrological SPS might be related to the nephrotoxicity of COVID-19 treatment. However, this has been mainly associated with remdesivir [52], which was not involved in therapeutic approaches in our cohort during the first wave of the pandemic. The most important aspect of these SPS is their strong association with negative outcomes in our study. Therefore, patients who develop nephrological symptomatology after discharge should be especially monitored, as these SPS could signal a particularly vulnerable patient profile [53].

\section{Haematological SPS}

In agreement with other studies that reported this relationship very early $[54,55]$, our study shows thrombotic manifestations (4.4\%), namely deep vein thrombosis, acute pulmonary embolism or cerebral stroke as the main haematological SPS in our cohort.

\section{Urological SPS}

Urological SPS were present in $4.3 \%$ of the patients followed. Symptoms of voiding syndrome such as dysuria, oliguria or nocturia, but also haematuria were relatively frequent in our cohort. Although the impact of the pandemic on urological services has been studied [56], these symptoms have not been consistently associated with COVID-19.

\section{Otorhinolaryngological SPS}

We present $3.1 \%$ of otorhinolaryngological SPS. To the best of our knowledge, these are not well-known SPS of COVID-19, although some authors have pointed out their possible implications [57]. We observed 1.9\% of vertigo SPS reported (rotatory dizziness, tinnitus, etc.) after discharge. More data are still necessary to draw conclusions about this association.

\section{Endocrinological SPS}

The last group of SPS identified in our cohort were endocrinological SPS (1.5\%), especially uncontrolled glycaemia $(0.9 \%)$ in diabetic patients. This group was the only one that presented higher frequencies in men.

\section{Return to the Emergency Services}

This outcome has not yet been analysed in depth in previous studies. However, given the increasing number of patients discharged from COVID-19, the healthcare costs and the current saturation of the Emergency Services, it is important to detect which SPS cause patients to return to these services. Although we found a high frequency of patients who returned to the Emergency Services $(20.3 \%)$, it is possible that these data are even underestimated, given the high concern for seeking healthcare at the onset of the pandemic. In our cohort, it was interesting to find that previous diseases, dependency, living in residential care homes or prognostic scores showed no association with this return. However, visible or easily identifiable symptoms like dermatological SPS and persistent anosmia or dysgeusia (which did not increase the risk of mortality or hospital readmission in our cohort) were strongly associated with return to the Emergency Services. It is possible that these SPS could be appropriately addressed by primary care telephone consultations. SPS that showed association with other negative outcomes, such as thoracic pain, arrhythmia, fever and pneumonia, which are 
undoubtedly alarming symptoms, were also associated with necessary return to the Emergency Services. Recognition of the severity of COVID-19 symptoms is crucial for correct therapeutic management [11], which should also improve follow-up treatment. We believe that more information on the potential alarming symptoms of patients discharged from COVID-19 could be provided to patients and their caregivers to improve follow-up and preventive measures in primary care.

\section{Limitations}

We present the prevalence of SPS during the 6 months after discharge of patients hospitalized for COVID-19. No distinctions were made between early or long-term SPS and any interpretation of the results of this study should take into account that our exposures are SPS during the 6 months after discharge, at any time point. Since the data assessment was collected retrospectively and no prior standardization of SPS was designed, analytical associations through OR are of limited value and should be interpreted with caution. However, we present these results as potential risk factors to be considered in future longitudinal studies. Also, we cannot confirm that these SPS are a consequence of COVID-19, as there is no available comparison group (prevalence of all SPS in patients that did not suffer from COVID-19). We attempted to minimize this limitation by suggesting only potential risk factors to be taken into account during patient follow-up and analysing their relationship with potential negative outcomes in adjusted models. However, the adjusted models could not be well optimized for two outcomes: hospital readmission and death after discharge, given their small sample size (35 and 8, respectively). Therefore, both models were adjusted for a small number of variables and the validation criteria were not always optimal. Given this limitation, associations on post-discharge death are only presented as Additional file 2: Table S5. In addition, obesity and smoking could not be adequately collected and, therefore, models were not adjusted for these important variables. The aim of this study, however, is to describe SPS and propose (but not corroborate or conclude) possible risk factors on negative outcomes.

Our study is also conducted in a sample of high-risk COVID-19 patients (i.e. those who required hospitalization). Therefore, the results regarding SPS frequencies and association with outcomes could not be extrapolated to all COVID-19 patients, but only to those who required hospital care. Also, the SPS reported by this cohort could be attributable to COVID-19 or could be partially explained by the hospitalization process and the treatment received.

The study was conducted during the first wave of COVID-19, when diagnostic and therapeutic protocols were different from the current ones. This bias was addressed by adjusting all associations for diagnostic and therapeutic variables.

Finally, our study was conducted in Spain. External validity may be biased given that the life expectancy, health care and baseline characteristics of Spanish patients cannot be extrapolated to other countries. We tried to minimize this effect by designing a multicentre study including 4 different hospitals and 969 patients. The results of this study could be applied to the Spanish population but should be included in systematic reviews and compared with international samples to optimize accurate conclusions.

\section{Conclusions}

Patients who required hospitalization for COVID-19 during the first wave in Spain presented a high frequency of SPS (63.9\%) during the first 6 months after discharge. We presented a detailed list of SPS and their frequency, stratified by sex. The most frequent groups were respiratory, systemic, neurological, mental health, superinfection and dermatological SPS. We also presented the association of these SPS with negative outcomes (return to the Emergency Services, hospital readmission and death after discharge). In sum, the presence of persistent fever, pneumonia, nephrological SPS and pressure ulcers indicated a high-risk patient profile.

Follow-up strategies should be optimized to avoid negative outcomes and to individualize preventive measures from primary care follow-up in subsequent waves.

\section{Supplementary Information}

The online version contains supplementary material available at https://doi. org/10.1186/s12916-021-02003-7.

\section{Additional file 1: STROBE checklist. Checklist of items included in reports of observational studies. \\ Additional file 2: Tables S1 to S5 (detailed information on secondary statistical results and data collection). Table S1. Sequelae or persistent symptoms (SPS) during 6 months after discharge: description and definitions of the information collected. Table S2. Sequelae or persistent symptoms (SPS) during 6 months after discharge associated to follow-up outcomes: return to emergency care, hospital readmission and post- discharge death. Table S3. Factors associated with the return to Emer- gency Services during the 6 months after discharge for COVID-19 hospitalization ( $n=160$ ). Crude and adjusted logistic regression models. Table S4. Factors associated with hospital readmission during the 6 months after discharge for COVID-19 first hospitalization $(n=35)$. Crude and adjusted logistic regression models. Table S5. Factors associated with mortality during the 6 months after discharge for COVID-19 hospitalization ( $n=8)$. Crude and adjusted logistic regression models.}

\section{Acknowledgements}

We thank the Chair of Teaching and Research in Family Medicine SEMERG EN-UGR for supporting this work. We also thank all the healthcare professionals of the Preventive Medicine and Public Health services of the Hospital San Cecilio, Reina Sofía, Jaén and Puerto Real for their ideas and support, and Ángela Rivera-Izquierdo for improving the use of English in the manuscript. 


\section{Authors' contributions}

MR-I and AC-C conceived and initiated the Andalusian Cohort of Hospitalized patients for COVID-19 (ANCOHVID) study, supervised its conduct and reviewed and commented on the draft. AR-D drafted and revised the manuscript and interpreted the analyses. EJ-M supervised the methodology and analyses. MR-I did all data analyses. All other authors coordinated the study in their respective centres, provided comments on drafts of the manuscript for important intellectual content and approved the final manuscript. The corresponding author attests that all listed authors meet authorship criteria and that no others meeting the criteria have been omitted. All authors read and approved the final version of the manuscript.

\section{Funding}

This study was supported by the Chair of Teaching and Research in Family Medicine SEMERGEN-UGR, University of Granada.

\section{Availability of data and materials}

Data described in the manuscript and the analytical code will be made available during ANCOHORT study conduct only to the investigators who have participated in/contributed to the study. Select summary data may be shared with policy makers for specific purposes. The study executive will consider specific requests for data analyses by non-contributing individuals upon reasonable request to the corresponding author.

\section{Declarations}

\section{Ethics approval and consent to participate}

This study was conducted under approvals from the Provincial Research Ethical Committee of Granada, Cádiz, Cordoba and Jaén. Datasets were anonymized before analyses.

\section{Consent for publication}

Not applicable

\section{Competing interests}

The authors declare that they have no competing interests.

\section{Author details}

${ }^{1}$ School of Medicine, University of Granada, Granada, Spain. ${ }^{2}$ Service of Preventive Medicine and Public Health, Hospital Universitario Clínico San Cecilio, Granada, Spain. ${ }^{3}$ Department of Preventive Medicine and Public Health, University of Granada, Avda. de la Investigación n¹1, 18016 Granada, Spain. ${ }^{4}$ Instituto de Investigación Biosanitaria, ibs.GRANADA, Granada, Spain. ${ }^{5}$ Service of Preventive Medicine and Public Health, Complejo Hospitalario de Jaén, Jaén, Spain. ${ }^{6}$ Service of Preventive Medicine and Public Health, Hospital Universitario de Puerto Real, Puerto Real, Cádiz, Spain. ${ }^{7}$ Unidad de Gestión Clínica Interniveles de Prevención, Promoción y Vigilancia de la Salud, Hospital Universitario Reina Sofía, Córdoba, Spain. ${ }^{8}$ Instituto Maimónides de Investigación Biomédica de Córdoba (Imibic), Córdoba, Spain. ${ }^{9}$ Chair of Teaching and Research in Family Medicine, SEMERGEN-UGR, University of Granada, Granada, Spain. ${ }^{10}$ Intensive Care Unit, Hospital de Poniente, El Ejido, Almería, Spain

\section{Received: 22 February 2021 Accepted: 10 May 2021}

\section{Published online: 20 May 2021}

\section{References}

1. Leung K, Wu JT, Liu D, Leung GM. First-wave COVID-19 transmissibility and severity in China outside Hubei after control measures, and second-wave scenario planning: a modelling impact assessment. Lancet. 2020;395(10233): 1382-93. https://doi.org/10.1016/S0140-6736(20)30746-7.

2. Van Damme W, Dahake R, Delamou A, Ingelbeen B, Wouters E, Vanham G, et al. The COVID-19 pandemic: diverse contexts; different epidemics-how and why? BMJ Glob Health. 2020;5(7):e003098. https://doi.org/10.1136/ bmjgh-2020-003098.

3. Jain V, Yuan JM. Predictive symptoms and comorbidities for severe COVID19 and intensive care unit admission: a systematic review and meta-analysis. Int J Public Health. 2020;65(5):533-46. https://doi.org/10.1007/s00038-02001390-7.

4. Chakraborty C, Sharma AR, Sharma G, Bhattacharya M, Lee SS. SARS-CoV-2 causing pneumonia-associated respiratory disorder (COVID-19): diagnostic and proposed therapeutic options. Eur Rev Med Pharmacol Sci. 2020;24: 4016-26 https://doi.org/10.26355/eurrev_202004_20871.

5. Ye Z, Zhang Y, Wang Y, Huang Z, Song B. Chest CT manifestations of new coronavirus disease 2019 (COVID-19): a pictorial review. Eur Radiol. 2020; 30(8):4381-9. https://doi.org/10.1007/s00330-020-06801-0.

6. Wan DY, Luo XY, Dong W, Zhang ZW. Current practice and potential strategy in diagnosing COVID-19. Eur Rev Med Pharmacol Sci. 2020;24(8): 4548-53. https://doi.org/10.26355/eurrev_202004_21039.

7. Rivera-Izquierdo M, Del Carmen V-UM, R-delAmo JL, Fernández-García MÁ Martínez-Diz S, Tahery-Mahmoud A, et al. Sociodemographic, clinical and laboratory factors on admission associated with COVID-19 mortality in hospitalized patients: a retrospective observational study. PLoS One. 2020; 15(6):e0235107. https://doi.org/10.1371/journal.pone.0235107.

8. Rivera-Izquierdo M, Valero-Ubierna MDC, R-delAmo JL, Fernández-García MÁ, Martínez-Diz S, Tahery-Mahmoud A, et al. Therapeutic agents tested in 238 COVID-19 hospitalized patients and their relationship with mortality. Med Clin (Barc). 2020;155:375-81 https://doi.org/10.1016/.jmedcli.2020.06.025.

9. Rivera-lzquierdo M, Valero-Ubierna MDC, Martínez-Diz S, Fernández-García MÁ, Martín-Romero DT, Maldonado-Rodríguez F, et al. Clinical factors, preventive behaviours and temporal outcomes associated with COVID-19 infection in health professionals at a Spanish hospital. Int J Environ Res Public Health. 2020;17(12):4305. https://doi.org/10.3390/ijerph17124305.

10. Berenguer J, Ryan P, Rodríguez-Baño J, Jarrín I, Carratalà J, Pachón J, et al. Characteristics and predictors of death among 4035 consecutively hospitalized patients with COVID-19 in Spain. Clin Microbiol Infect. 2020; 26(11):1525-36. https://doi.org/10.1016/j.cmi.2020.07.024.

11. Tsatsakis A, Calina D, Falzone L, Petrakis D, Mitrut R, Siokas V, et al. SARSCoV-2 pathophysiology and its clinical implications: an integrative overview of the pharmacotherapeutic management of COVID-19. Food Chem Toxicol. 2020;146:111769 https://doi.org/10.1016/j.fct.2020.111769.

12. Garrigues E, Janvier P, Kherabi Y, Le Bot A, Hamon A, Gouze H, et al. Postdischarge persistent symptoms and health-related quality of life after hospitalization for COVID-19. J Infect. 2020;81(6):e4-6. https://doi.org/10.101 6/j.jinf.2020.08.029.

13. Wang F, Kream RM, Stefano GB. Long-term respiratory and neurological sequelae of COVID-19. Med Sci Monit. 2020;26:e928996 https://doi.org/10.12 659/MSM.928996.

14. Wollina U, Karadağ AS, Rowland-Payne C, Chiriac A, Lotti T. Cutaneous signs in COVID-19 patients: a review. Dermatol Ther. 2020;33(5):e13549. https:// doi.org/10.1111/dth.13549.

15. Bolay H, Gül A, Baykan B. COVID-19 is a real headache! Headache. 2020; 60(7):1415-21. https://doi.org/10.1111/head.13856.

16. Huang C, Huang L, Wang Y, Li X, Ren L, Gu X, et al. 6-month consequences of COVID-19 in patients discharged from hospital: a cohort study. Lancet. 2021;397(10270):220-32 https://doi.org/10.1016/S0140-6736(20)32656-8.

17. Goërtz YMJ, Van Herck M, Delbressine JM, Vaes AW, Meys R, Machado FVC, et al. Persistent symptoms 3 months after a SARS-CoV-2 infection: the postCOVID-19 syndrome? ERJ Open Res. 2020;6(4):00542-2020. https://doi.org/1 $0.1183 / 23120541.00542-2020$

18. Moreno-Pérez O, Merino E, Leon-Ramirez JM. Post-acute COVID-19 syndrome. Incidence and risk factors: a Mediterranean cohort study. I Infect. 2021;S0163-4453(21):00009-8 https://doi.org/10.1016/j.jinf.2021.01.004.

19. Rosales-Castillo A, García de Los Ríos C, Mediavilla García JD. Persistent symptoms after acute COVID-19 infection: importance of follow-up. Med Clin (Barc). 2021;156:35-6. https://doi.org/10.1016/.medcli.2020.08.001.

20. Carfi A, Bernabei R, Landi F. Gemelli Against COVID-19 Post-Acute Care Study Group. Persistent symptoms in patients after acute COVID-19. JAMA. 2020;324(6):603-5. https://doi.org/10.1001/jama.2020.12603.

21. Giacomelli A, Ridolfo AL, Milazzo L, Oreni L, Bernacchia D, Siano M, et al. 30day mortality in patients hospitalized with COVID-19 during the first wave of the Italian epidemic: a prospective cohort study. Pharmacol Res. 2020; 158:104931 https://doi.org/10.1016/j.phrs.2020.104931.

22. Bastos GAN, Azambuja AZ, Polanczyk CA, Gräf DD, Zorzo IW, Maccari JG, et al. Clinical characteristics and predictors of mechanical ventilation in patients with COVID-19 hospitalized in Southern Brazil. Rev Bras Ter Intensiva. 2020;32(4):487-92. https://doi.org/10.5935/0103-507X.20200082.

23. Casas-Rojo JM, Antón-Santos JM, Millán-Núñez-Cortés J, Lumbreras-Bermejo C, Ramos-Rincón JM, Roy-Vallejo E, et al. Clinical characteristics of patients hospitalized with COVID-19 in Spain: results from the SEMI-COVID-19 Registry. Rev Clin Esp. 2020;220(8):480-94. https://doi.org/10.1016/j.rce.2020. 07.003. 
24. Spanish National Center of Epidemiology. National Epidemiological Surveillance Network. Report on COVID-19 situation in Spain. Report 14, 2020. https://www.isciii.es/QueHacemos/Servicios/VigilanciaSa ludPublicaRENAVE/EnfermedadesTransmisibles/Paginas/ InformesCOVID-19.aspx.

25. Zueras P, Rentería E. Trends in disease-free life expectancy at age 65 in Spain: diverging patterns by sex, region and disease. PLoS One. 2020;15(11): e0240923. https://doi.org/10.1371/journal.pone.0240923.

26. Ramón Martínez Riera J, Gras-Nieto E. Atención domiciliaria y COVID-19. Antes, durante y después del estado de alarma [Home care and COVID_19. Before, in and after the state of alarm]. Enferm Clin. 2020; https://doi.org/1 0.1016/j.enfcli.2020.05.003.

27. Richardson S, Hirsch JS, Narasimhan M, Crawford JM, McGinn T, Davidson KW, et al. Presenting characteristics, comorbidities, and outcomes among 5700 patients hospitalized with COVID-19 in the New York City area. JAMA 2020;323:2052-9 https://doi.org/10.1001/jama.2020.6775. Erratum in: JAMA. 2020;323:2098.

28. Zhou F, Yu T, Du R, Fan G, Liu Y, Liu Z, et al. Clinical course and risk factors for mortality of adult inpatients with COVID-19 in Wuhan, China: a retrospective cohort study. Lancet. 2020;395:1054-62 https://doi.org/10.101 6/S0140-6736(20)30566-3. Erratum in: Lancet. 2020;395:1038.

29. Carvalho-Schneider C, Laurent E, Lemaignen A, Beaufils E, Bourbao-Tournois C, Laribi S, et al. Follow-up of adults with noncritical COVID-19 two months after symptom onset. Clin Microbiol Infect. 2020;\$1198-743X(20):30606 https://doi.org/10.1016/j.cmi.2020.09.052

30. Halpin SJ, Mclvor C, Whyatt G, Adams A, Harvey O, McLean L, et al. Postdischarge symptoms and rehabilitation needs in survivors of COVID-19 infection: a cross-sectional evaluation. J Med Virol. 2021;93(2):1013-22. https://doi.org/10.1002/jmv.26368.

31. Vasarmidi E, Tsitoura E, Spandidos DA, Tzanakis N, Antoniou KM, et al, Pulmonary fibrosis in the aftermath of the COVID-19 era (review). Exp Ther Med. 2020;20:2557-60 https://doi.org/10.3892/etm.2020.8980.

32. Townsend L, Dyer AH, Jones K, Dunne J, Mooney A, Gaffney F, et al. Persistent fatigue following SARS-CoV-2 infection is common and independent of severity of initial infection. PLoS One. 2020;15(11):e0240784. https://doi.org/10.1371/journal.pone.0240784.

33. Feng X, Li S, Sun Q, Zhu J, Chen B, Xiong M, et al. Immune-inflammatory parameters in COVID-19 cases: a systematic review and meta-analysis. Front Med (Lausanne). 2020;7:301 https://doi.org/10.3389/fmed.2020.00301.

34. García LF. Immune response, inflammation, and the clinical spectrum of COVID-19. Front Immunol. 2020;11:1441 https://doi.org/10.3389/fimmu.2020. 01441.

35. Zekarias A, Watson S, Vidlin SH, Grundmark B. Sex differences in reported adverse drug reactions to COVID-19 drugs in a global database of individual case safety reports. Drug Saf. 2020;43(12):1309-14. https://doi.org/10.1007/s4 0264-020-01000-8.

36. Zhong $P, X u$ J, Yang D, Shen Y, Wang L, Feng Y, et al. COVID-19-associated gastrointestinal and liver injury: clinical features and potential mechanisms. Signal Transduct Target Ther. 2020;5(1):256. https://doi.org/10.1038/s41392020-00373-7.

37. Heneka MT, Golenbock D, Latz E, Morgan D, Brown R, et al. Immediate and long-term consequences of COVID-19 infections for the development of neurological disease. Alzheimers Res Ther. 2020;12(1):69. https://doi.org/1 0.1186/s13195-020-00640-3.

38. Sharifian-Dorche M, Huot P, Osherov M, Wen D, Saveriano A, Giacomini PS, et al. Neurological complications of coronavirus infection; a comparative review and lessons learned during the COVID-19 pandemic. J Neurol Sci. 2020;417:117085 https://doi.org/10.1016/j.jns.2020.117085.

39. Pennisi M, Lanza G, Falzone L, Fisicaro F, Ferri R, Bella R. SARS-CoV-2 and the nervous system: from clinical features to molecular mechanisms. Int J Mol Sci. 2020;21(15):5475 https://doi.org/10.3390/ijms21155475.

40. Fisicaro F, Di Napoli M, Liberto A, Fanella M, Di Stasio F, Pennisi M, et al. Neurological sequelae in patients with COVID-19: a histopathological perspective. Int J Environ Res Public Health. 2021;18(4):1415 https://doi.org/1 0.3390/ijerph18041415

41. Katyal N, Narula N, Acharya S, Govindarajan R. Neuromuscular complications with SARS-COV-2 infection: a review. Front Neurol. 2020;11:1052 https://doi. org/10.3389/fneur.2020.01052.

42. Rogers JP, Chesney E, Oliver D, Pollak TA, McGuire P, Fusar-Poli P, et al Psychiatric and neuropsychiatric presentations associated with severe coronavirus infections: a systematic review and meta-analysis with comparison to the COVID-19 pandemic. Lancet Psychiatry. 2020;7(7):611-27. https://doi.org/10.1016/\$2215-0366(20)30203-0.

43. Lamprecht B. Gibt es ein Post-COVID-Syndrom? [ls there a post-COVID syndrome?]. Pneumologe (Berl). 2020:1-4 https://doi.org/10.1007/s10405-02 0-00347-0.

44. Ren $X$, Huang $W$, Pan $H$, Huang $T$, Wang $X$, Ma Y. Mental health during the Covid-19 outbreak in China: a meta-analysis. Psychiatr Q. 2020;91(4):1033-45. https://doi.org/10.1007/s11126-020-09796-5.

45. Webb L. COVID-19 lockdown: a perfect storm for older people's mental health. J PsychiatrMent Health Nurs. 2020; https://doi.org/10.1111/jpm.12 644.

46. Carrascosa JM, Morillas V, Bielsa I, Munera-Campos M. Cutaneous manifestations in the context of SARS-CoV-2 infection (COVID-19). Actas Dermosifiliogr. 2020;111(9):734-42. https://doi.org/10.1016/j.ad.2020.08.002

47. Madjid M, Safavi-Naeini P, Solomon SD, Vardeny O. Potential effects of coronaviruses on the cardiovascular system: a review. JAMA Cardiol. 2020; 5(7):831-40. https://doi.org/10.1001/jamacardio.2020.1286.

48. Mitrani RD, Dabas N, Goldberger JJ. COVID-19 cardiac injury: implications for long-term surveillance and outcomes in survivors. Heart Rhythm. 2020; 17(11):1984-90. https://doi.org/10.1016/j.hrthm.2020.06.026.

49. Barnes M, Heywood AE, Mahimbo A, Rahman B, Newall AT, Macintyre CR. Acute myocardial infarction and influenza: a meta-analysis of case-control studies. Heart. 2015;101(21):1738-47. https://doi.org/10.1136/heartjnl-2015-3 07691.

50. Xiong Q, Xu M, Li J, Liu Y, Zhang J, Xu Y, et al. Clinical sequelae of COVID-19 survivors in Wuhan, China: a single-centre longitudinal study. Clin Microbiol Infect. 2021;27(1):89-95. https://doi.org/10.1016/j.cmi.2020.09.023.

51. Romano MR, Montericcio A, Montalbano C, Raimondi R, Allegrini D, Ricciardelli G, et al. Facing COVID-19 in ophthalmology department. Curr Eye Res. 2020;45(6):653-8. https://doi.org/10.1080/02713683.2020.1752737.

52. Grein J, Ohmagari N, Shin D, Diaz G, Asperges E, Charan J, et al. Rapid review of suspected adverse drug events due to remdesivir in the $\mathrm{WHO}$ database; findings and implications. Expert Rev Clin Pharmacol. 2020;29(1): 1-9. https://doi.org/10.1080/17512433.2021.1856655

53. Bruchfeld A. The COVID-19 pandemic: consequences for nephrology. Nat Rev Nephrol. 2021;17(2):81-2. https://doi.org/10.1038/s41581-020-00381-4.

54. Mina A, van Besien K, Platanias LC. Hematological manifestations of COVID19. LeukLymphoma. 2020;61(12):2790-8. https://doi.org/10.1080/10428194.2 020.1788017.

55. Frater JL, Zini G, d'Onofrio G, Rogers HJ. COVID-19 and the clinical hematology laboratory. Int J Lab Hematol. 2020;42(S1):11-8. https://doi. org/10.1111/ijlh.13229.

56. Teoh JY, Ong WLK, Gonzalez-Padilla D, Castellani D, Dubin JM, Esperto F, et al. A global survey on the impact of COVID-19 on urological services. Eur Urol. 2020;78(2):265-75. https://doi.org/10.1016/j.eururo.2020.05.025.

57. Krajewska J, Krajewski W, Zub K, Zatoński T. COVID-19 in otolaryngologist practice: a review of current knowledge. Eur Arch Otorhinolaryngol. 2020; 277(7):1885-97. https://doi.org/10.1007/s00405-020-05968-y.

\section{Publisher's Note}

Springer Nature remains neutral with regard to jurisdictional claims in published maps and institutional affiliations.

Ready to submit your research? Choose BMC and benefit from:

- fast, convenient online submission

- thorough peer review by experienced researchers in your field

- rapid publication on acceptance

- support for research data, including large and complex data types

- gold Open Access which fosters wider collaboration and increased citations

- maximum visibility for your research: over $100 \mathrm{M}$ website views per year

At $\mathrm{BMC}$, research is always in progress.

Learn more biomedcentral.com/submissions 